\title{
Sitosterol Blood Levels are Elevated in Diabetics and may be the Cause of Coronary Artery Disease and Stroke
}

\author{
Gabriel M Khan
}

\section{ABSTRACT}

Introduction: Worldwide, diabetes is on the rise. Tight glucose control in randomized control trials has not shown significant improvement in cardiovascular outcomes. It is true that hyperglycemia causes a metabolic syndrome and low-density lipoprotein-cholesterol increases, but atheromatous coronary artery disease (CAD) and cerebrovascular disease are not completely curbed by marked reduction of hyperglycemia. It is necessary, therefore, to search for other culprits that cause atheroma.

High blood sitosterol causes atheromatous CAD and fatal myocardial infarction in young adults with sitosterolemia, in which mutations in either ABCG5 or G8 proteins cause intestinal hyperabsorption of sitosterol and elevated levels. A milder intestinal genetic defect [ABCG5/G8] is present in diabetics. This fact is unknown to endocrinologists, doctors in the field, researchers, and the public. Diabetics consume much vegetable foods that contain sitosterol. The aim of this study is simply to determine if fasting blood sitosterol is elevated in diabetics, particularly in those with CAD.

Materials and methods: Estimation for sitosterol was performed at the Mayo Medical Laboratories for 40 patients with type II diabetes and 17 control subjects.

Results: Sitosterol was elevated in $45 \%$ of diabetics, and normal in $100 \%$ control subjects; $78.26 \%$ of diabetic subjects with CAD showed elevated fasting blood sitosterol levels, 5.1 to $9.5 \mathrm{mg} / \mathrm{L}$ (normal range $0-4.9 \mathrm{mg} / \mathrm{L}$ ).

Conclusion: This novel but preliminary study shows that 12 to 14 hours fasting blood sitosterol levels are elevated in patients with diabetes particularly in diabetics with CAD. The objective was achieved. Most diabetics have elevated blood sitosterol and require treatment as is done for familial homozygous sitosterolemia.

Keywords: Atheroma, Blood elevation, Coronary artery disease, Diabetic, Sitosterol.

How to cite this article: Khan GM. Sitosterol Blood Levels are Elevated in Diabetics and may be the Cause of Coronary Artery Disease and Stroke. J Med Sci 2017;3(2):89-94.

Source of support: Nil

Conflict of interest: None

\section{Cardiologist}

Department of Cardiology, Bank Medical Research Centre Ottawa, Ontario, Canada

Corresponding Author: Gabriel M Khan, Cardiologist Department of Cardiology, Bank Medical Research Centre Ottawa, Ontario, Canada, Phone: +6135212564 , e-mail: khanbooks@rogers.com

\section{KEY QUESTIONS}

\section{What is Already Known about this Subject?}

- Abnormally high blood sitosterol causes atheromatous coronary artery disease (CAD) and fatal myocardial infarction (MI) in young adults with sitosterolemia in which mutations in either ABCG5 or G8 proteins cause intestinal hyperabsorption of sitosterol.

- Sitosterol is a widely used herbal remedy. Diabetics restrict carbohydrates and, of necessity, consume much plant foods containing sitosterol.

- Worldwide, diabetes is on the rise; MI is a frequent outcome. About 1 million diabetics die annually in India. Tight glucose control in randomized controlled trials has not shown significantly improved outcomes mainly because hyperglycemia does not cause atherosclerosis.

\section{What does this Study Add?}

- This novel but preliminary study is the first to show that 12 to 14 hours fasting sitosterol blood levels are abnormally high in patients with type II diabetes mellitus, particularly in those with CAD, with levels reaching $100 \%$ more than observed in nondiabetic vegetarians.

- Dietary restriction of sitosterol-containing foods and treatment with ezetimibe or with more effective agents to be developed would improve outcomes, particularly heart attacks, stroke, nephropathy, and perhaps blindness in diabetic patients. Lives would be saved.

\section{How might this Impact on Clinical Practice?}

- A new treatment strategy should evolve for patients with diabetes. This study shows that diabetics have sitosterolemia and require the same drug and dietary treatment offered to patients with familial sitosterolemia.

\section{INTRODUCTION}

Cardiovascular disease (CVD) is the most common cause of death among adults with diabetes mellitus. ${ }^{1}$ Patients with type II diabetes mellitus without a history of myocardial infarction (MI) appear to have about the same risk 
of a coronary event as patients without diabetes who do have a history of $\mathrm{MI}^{2}{ }^{2}$ Heart disease death rates among adults with diabetes mellitus are two to four times higher than the rates for adults without diabetes. ${ }^{2}$

Tight glucose control in large randomized controlled trials has not shown significant improvement in cardiovascular outcomes. ${ }^{3-5}$ Atheromatous CAD is not completely curbed by reduction of hyperglycemia or lowdensity lipoprotein cholesterol (LDL-C). It is necessary, therefore, to search for other culprits that cause atheroma.

Elevated blood sitosterol causes atheromatous CAD, fatal MI, and CVD in young adults with sitosterolemia. ${ }^{6-8}$ Bhattacharyya and Connor ${ }^{7}$ reported on a newly described lipid storage disease in two sisters. Because of markedly elevated plasma and tissue sitosterol levels, premature atherosclerosis develops.

Salen et $\mathrm{al}^{6}$ described the autopsy findings from an 18-year-old white male who died suddenly of an acute MI. From age 10, he had noted tendon xanthomas that began on the left elbow and back and then subsequently in the Achilles tendons, knees, and wrists. Measurements of plasma sterols 4 years prior to death revealed high concentrations of plant sterols with mild hypercholesterolemia and a diagnosis of sitosterolemia with xanthomatosis was established. ${ }^{7}$ The genetic disease sitosterolemia is marked by mutations in either ABCG5 or G8 proteins ${ }^{8}$ that cause intestinal hyperabsorption of sitosterol., ${ }^{9,10}$ A less severe intestinal genetic defect (ABCG5 or G8 proteins) is present in diabetics. Hyperabsorption of sitosterol was shown to occur in a small study of six diabetic subjects. ${ }^{10}$

Because of carbohydrate restrictions, diabetics consume much vegetable plant foods containing sitosterol, a probable culprit. The study aimed, therefore, to assess fasting blood sitosterol levels in diabetics, particularly in those with CAD.

\section{MATERIALS AND METHODS}

Ethics review was attained from Canadian Shield Ethics Review Board, and consent was signed. The author designed the study, gathered the data, made the analysis along with deductions, and decision to submit the manuscript for publication. A total of 57 patients aged 35 to 82 years were studied; 40 with type II diabetes and 17 nondiabetic controls; 28 (49.1\%) were Caucasian, $24(\sim 42.1 \%)$ Asian, and 8.7\% others. The diabetic group included 24 patients with proven CAD (57.5\%) and 16 $(42.5 \%)$ with hypertension, arrhythmia, or valvular heart disease.

Blood sitosterol estimation and albumin creatinine ratio was done for each diabetic patient. The frozen specimen was transported on dry ice from an Ottawa laboratory to the Mayo Medical Laboratories. Sitosterol levels were obtained by gas-liquid chromatography. All diabetic and nondiabetic control subjects were requested to have an evening meal with much vegetable, the evening before, and blood drawn 12 to 13 hours after food. Subjects were considered mild diabetics if during the prior 4 years only one oral drug, or two oral drugs at nonmaximal doses were needed for control, and fasting blood glucose (FBG) never exceeded $10 \mathrm{mmol} / \mathrm{L}$. Sitosterol was elevated in $34.37 \%$ of mild diabetics and in $54.54 \%$ with moderately severe disease. Subjects were considered moderately severe diabetics if two drugs at full doses, or insulin was required and FBG was known to exceed $11 \mathrm{mmol} / \mathrm{L}$ on several occasions. Subjects with type 2 diabetes mellitus, duration $>10$ years, on two oral drugs, one at full dose, second at half dosage were considered to have diabetes of moderate intensity. A more stringent method for determining severity was not needed.

\section{RESULTS}

The author vouches for the accuracy and completeness of the data and analyses, and for the fidelity of this report. The results of all subjects enrolled were analyzed, with no exclusions.

\section{Sitosterol Levels in Diabetics}

About $45 \%$ of all diabetic subjects and $78.26 \%$ of diabetics with CAD showed elevated fasting blood sitosterol levels: 5.1 to $9.5 \mathrm{mg} / \mathrm{L}$ (normal range $0-5 \mathrm{mg} / \mathrm{L}$ ) (Table 1).

\section{Controls}

A total of $100 \%$ showed normal sitosterol levels: Nonvegetarians who consumed mostly a vegetable meal showed 1 to $3.6 \mathrm{mg} / \mathrm{L}$. Vegetarians who consumed a large vegetable meal showed levels, 4 to $4.6 \mathrm{mg} / \mathrm{L}$ (Table 2). Diabetic subjects showed sitosterol levels, 7 to $9.5 \mathrm{mg} / \mathrm{L}$; 75 to $100 \%$ more than nondiabetic vegetarians. This study shows that diabetics have elevated blood sitosterol.

Conversion factor: Sitosterol: 2.42X; Campesterol: 2.5X $\mu \mathrm{M} / \mathrm{L}$

Sitosterol 0 to $5 \mathrm{mg} / \mathrm{L}=0$ to $12.1 \mu \mathrm{M} / \mathrm{L}$

Campesterol 0 to $7 \mathrm{mg} / \mathrm{L}=0$ to $17.5 \mu \mathrm{M} / \mathrm{L}$

Abnormal albumin creatinine ratio (ACR): A total of $50 \%$ of subjects with an ACR $>2 \mathrm{mg} / \mathrm{mmol}$ had an elevated sitosterol level; all had CAD.

Campesterol: Both sitosterol and campesterol are hyperabsorbed in diabetics. But campesterol is not known to be harmful. For each diabetic subject with an elevated fasting blood sitosterol, the campesterol level was abnormally elevated, 7.4 to $15.7 \mathrm{mg} / \mathrm{L}$ (normal 
Table 1: Albumin creatinine ratio, (ALB/CR) sitosterol and campesterol blood levels, and presence of CVD for each diabetic subject

\begin{tabular}{|c|c|c|c|c|c|c|}
\hline Subject & $\begin{array}{l}\text { Albumin } \\
\text { creatinine ratio }\end{array}$ & Microalbumin & Diabetes severity & Sitosterol mg/L & Campesterol & Vascular disease \\
\hline *1 & 271 & 2336 & +++ & 9.0 & 8.3 & CAD; nephropathy \\
\hline 2 & 1.3 & 13.7 & + & 5.3 & 8.3 & CAD \\
\hline 3 & 0.5 & $<5$ & + & 9.2 & 7.2 & CAD \\
\hline 4 & $<2$ & 22 & + & 5.1 & 7.8 & CAD \\
\hline 5 & 13.2 & 179 & +++ & 5.4 & 6.8 & CAD; nephropathy \\
\hline${ }^{* *} 6$ & 3.9 & 42.8 & +++ & 6.6 & 7.4 & CAD; nephropathy \\
\hline 7 & $<2$ & $<5$ & +++ & 6.3 & 9.2 & CAD \\
\hline$* * 8$ & 185 & 77 & +++ & 8.3 & 11.2 & CAD; nephropathy \\
\hline 9 & $<1.0$ & 6.9 & + & 5.2 & 6.4 & CAD \\
\hline 10 & 11 & 3.7 & + & 3.2 & 4.1 & CAD \\
\hline 11 & $<1$ & 7.3 & ++ & 2.9 & 4.2 & $\mathrm{BP}$ \\
\hline 12 & $<1$ & 7.3 & + & 2.6 & 4.1 & $\mathrm{BP}$ \\
\hline 13 & $<1$ & 5.6 & + & 4.1 & 4.8 & CAD \\
\hline 14 & $<2$ & $<5$ & + & 3.0 & 4.5 & $\mathrm{BP}$ \\
\hline 15 & $<2$ & $<5$ & + & 2.3 & 5.2 & $\mathrm{BP}$ \\
\hline$* * 16$ & 5.7 & 78.7 & + & 4.4 & 6.2 & CAD \\
\hline 17 & 1.9 & 5.3 & + & 6.1 & 8.0 & CAD \\
\hline 18 & $<2$ & $<5$ & +++ & 8.7 & 15.7 & CAD \\
\hline 19 & $<2$ & $<5$ & + & 5.2 & 8.0 & CAD \\
\hline 20 & $<2$ & $<5$ & ++ & 1.2 & 4.2 & $\mathrm{BP}$ \\
\hline$* * 21$ & $<1$ & 5.9 & + & 7.9 & 12.5 & CAD \\
\hline 22 & $<2$ & $<5$ & + & 1.2 & 2.0 & $\mathrm{BP}$ \\
\hline 23 & 1.2 & 15.2 & + & 6.4 & 10.8 & CAD \\
\hline 24 & $<2$ & $<1$ & + & 0.7 & 1.7 & BP \\
\hline${ }^{* *} 25$ & 3.3 & 36 & + & 4.2 & 6.0 & $\mathrm{BP}$ \\
\hline 26 & 8.9 & 96 & + & 2.8 & 4.2 & Arrhythmia \\
\hline **27 & 5.4 & 87.5 & +++ & 3.3 & 5.2 & CAD \\
\hline 28 & 4.3 & 73 & + & 3.7 & 6.8 & BP \\
\hline 29 & 5.2 & 20.2 & + & 6.9 & 7.8 & CAD \\
\hline$* * 30$ & $<1.0$ & 7.9 & + & 3.2 & 4.2 & $\mathrm{BP}$ \\
\hline 31 & $<2.0$ & $<2$ & + & 3.6 & 6.5 & BP \\
\hline 32 & $<2$ & $<2$ & + & 3.6 & 6.8 & $\mathrm{BP}$ \\
\hline *33 & 102.3 & 880.2 & + & 6.4 & 7.9 & CAD; nephropathy \\
\hline 34 & 1.2 & 9.5 & + & 3.6 & 2.5 & $\mathrm{BP}$ \\
\hline 35 & 2.7 & 17.3 & ++ & 3.7 & 5.3 & arrhythmia \\
\hline \#36 & 235.9 & 802.0 & ++ & 3.4 & 5.0 & CAD; nephropathy \\
\hline$\#_{37}$ & $<1$ & $<5$ & - & 5.4 & 9.4 & CAD \\
\hline 38 & $<2$ & $<5$ & ++ & 7.8 & 6.0 & CAD \\
\hline **39 & $<2$ & $<5$ & + & 4.2 & 7.5 & $\mathrm{BP}$ \\
\hline 40 & 0.8 & 3 & ++ & 3.5 & 6.5 & $\mathrm{BP}$ \\
\hline
\end{tabular}

CAD: Coronary artery disease; BP: Blood pressure; ${ }^{+}$Mild diabetes: One oral drug or two at half dosage; ${ }^{++}$Moderate intensity: Duration $>10$ years: On two oral drugs; one at full dose, second at half dosage; ${ }^{\# 6}$ : Patient disabled, vegetable meal intake night before test, unknown unreliable; ${ }^{\# 3}$ 3 proven diabetes mellitus: (-) very mild, on no medications: mother, father and 4 siblings all have diabetes; ${ }^{+++}$Moderately severe: Two oral drugs at maximum dose or added insulin; *e-glomerular filtration rate $<25 \mathrm{~mL} / \mathrm{min}$; ${ }^{* *}$ Test done $\sim 16$ hours after food

range $0-7 \mathrm{mg} / \mathrm{L}$ ) indicating reliability of the sitosterol elevations. Other plant sterols, desmosterol, and lathosterol levels were obtained but are not relevant because they are not known to cause atheroma. Only sitosterol is proven to cause atheroma.

\section{DISCUSSION}

This is the first study to show that in diabetics, 12 to 14 hours fasting blood sitosterol levels are abnormally increased, particularly in those with CAD. This increase can only occur if there is increased intestinal absorption of sitosterol and decreased hepatobiliary elimination.

Sitosterolemia is a recessively inherited disorder that results from mutations in either ABCG5 or G8 proteins, with increased absorption of dietary sterols and decreased hepatic excretion of plant sterols and cholesterol. ${ }^{8}$ A less intense genetic defect is present in diabetics. Sitosterol elevation added to LDL-C is the likely cause of MI, stroke, and peripheral vascular disease in diabetics. Sterolins ABCG5 and ABCG8 are regulators of whole body dietary sterols. ${ }^{9}$ The ATP-binding cassette transporters G5 and G8 


\begin{tabular}{|c|c|c|c|}
\hline $\begin{array}{l}\text { Control } \\
\text { subjects }\end{array}$ & Sitosterol, $\mathrm{mg} / \mathrm{L}$ & Campesterol & Vascular Disease \\
\hline 1 & 1.5 & 2.3 & CAD \\
\hline 2 & 2.4 & 3.5 & CAD \\
\hline 3 & 2.8 & 4.5 & $\mathrm{BP}$ \\
\hline 4 & 2.9 & 3.8 & CAD \\
\hline 5 & 2.8 & 5.9 & CAD \\
\hline 6 & 2.6 & 3.8 & CAD \\
\hline 7 & 1.2 & 3 & Cardiomyopathy \\
\hline 8 & 2.4 & 3.6 & CAD \\
\hline 9 & 2.0 & 3.3 & CAD \\
\hline 10 & 1.0 & 1.8 & CAD \\
\hline 11 & 1.4 & 1.6 & CAD \\
\hline 12 & 1.5 & 2.2 & CAD \\
\hline 13 & 3.6 & 6.5 & $\mathrm{BP}$ \\
\hline 14 & 2.3 & 2 & CAD \\
\hline \#15 & 4.2 & 6.7 & Cardiomyopathy \\
\hline \#16 & 4 & 6.8 & $\mathrm{BP}$ \\
\hline$\# 17$ & 4.2 & 8.5 & $\mathrm{BP}$ \\
\hline
\end{tabular}

CAD: Coronary artery disease; BP: Blood pressure; \#Vegetarian requested to have large vegetable meal with added avocado

(ABCG5 and ABCG8) play an important role in intestinal sterol absorption and bile acid secretion. ${ }^{9}$

The effect of sitosterol-enriched diet on chylomicron composition and the relationship between chylomicron sitosterol and intestinal ABCG5 and G8 and NPC1L1 gene expression were examined..$^{10}$ Six type II diabetic patients and six control subjects were studied. Subjects were given 1 week of sitosterol-enriched diet $(2.5 \mathrm{gm} /$ day), in which sitosterol-enriched margarine and milk or yogurt were substituted for their normal dairy products. ${ }^{10}$ Subjects had fasting blood taken, followed by a $4.60 \mathrm{MJ}$ (1100 kcal) high-fat test meal containing $2.0 \mathrm{gm}$ sitosterol and 4 and 6 hours following the meal blood was sampled. Postprandial chylomicron sitosterol was significantly increased in diabetic patients $(5.5 \pm 1.2$ vs $3.4 \pm 1.3 \mathrm{mg} /$ $\mathrm{mL}$ plasma, $\mathrm{p}<0.02) .{ }^{10}$

Fasting serum cholesterol for diabetic and control subjects was $5.0 \pm 0.9$ and $4.7 \pm 1.1 \mathrm{mmol} / \mathrm{L} .{ }^{10}$ Unfortunately, 12 to 16 hours fasting blood sitosterol levels were not estimated. But the study ${ }^{10}$ confirmed that intestinal absorption of sitosterol is increased in diabetics, and this is caused by a genetic abnormality at ABCG5 and ABCG8. Currently this information is unknown to endocrinologists and clinicians. Importantly, some diabetics have hyperglycemia and sitosterolemia, and therapy for both conditions is necessary.

A polymorphism of the sterol transporter ABCG8 has been associated with the prevalence of end-stage renal disease and with the incidence of new renal events in type II diabetic patients. ${ }^{11}$ The association of ABCG8 T400K polymorphism with renal disease was validated in the DIAB2NEPHROGENE population of patients with type II diabetes with duration of 16 years on average. ${ }^{12}$ This association of ABCG8 T400K polymorphism with renal disease ${ }^{12}$ appears validated, but confirmation is required. The possibility that sitosterol causes nephropathy cannot be simply excluded. Those who have viewed the pathologic kidney of Kimmelstiel-Wilson syndrome may agree that hyperglycemia is an unlikely cause for the severe derangement of morphology and function of the diabetic nephrotic kidney. About $50 \%$ of subjects with abnormal ACR (>2 mg/mmol) had elevated sitosterol levels but all had CAD.

Blood sitosterol is slightly higher in nondiabetic vegetarians 4.6 (4.3-4.9) $\mathrm{\mu g} / \mathrm{mL}$ compared with nonvegetarians, 3.9 (3.8-4.0) $\mu \mathrm{g} / \mathrm{mL}{ }^{13}$ Fasting blood sitosterol levels in diabetic vegetarians may be much higher than observed in our study of nonvegans (5.2-9.5 mg/L) and require assessment, particularly because much plant foods are consumed in underdeveloped and developing countries. Fasting plasma concentrations above $10 \mathrm{mg} / \mathrm{L}$ are diagnostic of genetic homozygous sitosterolemia. A level of 4.6 to $9.6 \mathrm{mg} / \mathrm{L}$ maintained more than 15 years in diabetics may cause atheromatous CAD.

Several small studies including that of Glueck et a ${ }^{14}$ have analyzed the association between plasma plantsterol levels and CVD, but have found conflicting results. ${ }^{15}$ Studies have not focused on diabetics and sitosterol, the only plant sterol known to cause atheroma and MI. PROCAM studied each of 159 men who suffered a MI or sudden coronary death within 10 years of follow-up and were matched with two controls $(n=318)$ by age, smoking status, and date of investigation. ${ }^{16}$ Analysis was performed using conditional logistic regression. Plasma sitosterol concentrations were mildly elevated in cases compared with controls $(4.94 \pm 3.44$ vs $4.27 \pm 2.38 \mu \mathrm{mol} / \mathrm{L}$; $\mathrm{p}=0.028)$. The upper quartile of sitosterol $(>5.25 \mu \mathrm{mol} / \mathrm{L})$ was associated with a 1.8 -fold increase in risk $(p<0.05)$ compared with the lower three quartiles. ${ }^{16}$ This small study did not include diabetics.

Miettinen et $a 1^{17}$ found that the higher the absorption of cholesterol, the higher is the plant sterol content of serum and atherosclerotic plaques, which they studied following carotid endarterectomy. In that study, in which they divided the plaques into high, medium, and low cholesterol, the low cholesterol plaques had the highest noncholesterol sterols. ${ }^{17}$ In 4 S, no reduction was observed in recurrence of coronary heart disease with simvastatin in patients with high baseline plant sterol contents and with marked increase of serum plant sterols during the 5 -year treatment period. But Miettinen et $\mathrm{al}^{18}$ assessed desmosterol lathosterol and campesterol. Only sitosterol, not tested by these investigators, is known to cause atheroma formation and progression. Also, simvastatin 
does not decrease levels of sitosterol because it does not prevent hyperabsorption of plant sterols.

Luister et $\mathrm{al}^{19}$ in a small study of 104 patients evaluated the relationship between phytosterols, oxyphytosterols, and other markers of cholesterol metabolism and concomitant CAD in patients with severe aortic stenosis who were scheduled for elective aortic valve replacement. The absolute values for the cholesterol absorption markers, sitosterol and campesterol, were increased by $18.18 \pm 11.59 \mathrm{ng} / \mathrm{mg}$ (38.8\%) and $11.40 \pm 8.69 \mathrm{ng} / \mathrm{mg}(30.4 \%)$ in aortic valve tissues from patients with documented CAD compared with those without concomitant CAD. The study of aortic valve tissues did not assess fasting sitosterol blood levels; diabetics were not studied. These studies ${ }^{17,19}$ have found sitosterol in valve tissue and atheroma plaque, and along with our study findings should engender large studies.

The study confirms that patients with type II diabetes mellitus hyperabsorb sitosterol because of an intestinal genetic defect similar to that of sitosterolemia. ${ }^{9,10}$ Hepatobiliary excretion may be decreased but the main abnormality is hyperabsorption.

Patients with type I diabetes require assessment, particularly those with retinopathy.

\section{LIMITATIONS}

Our study has several limitations: This is a small preliminary study. Findings need to be confirmed in large studies to show that diabetics, particularly those with atheroma, nephropathy, neuropathy, and diabetic retinopathy, have elevated sitosterol blood levels. Fortunately, this testing can be done in many endocrinology clinics and laboratories worldwide with results obtained within months.

\section{THERAPEUTIC AND RESEARCH IMPLICATIONS}

First, perhaps CVD in diabetics is caused by both elevated LDL-C and sitosterol. Second, perhaps a new treatment strategy can be added to current therapy for diabetics. This study shows that diabetics have sitosterolemia. Thus, some restriction of plant foods containing sitosterol may be advised following further studies. Effective sitosterol absorption inhibitors should be developed. Ezetimibe reduces both blood cholesterol and sitosterol levels and is used to treat familial sitosterolemia. ${ }^{20}$ Sitosterol concentrations decreased by $21 \%(p<0.001)$ in patients treated with ezetimibe compared with a nonsignificant $4 \%$ rise in those on placebo (between-group $p<0.001$ ). ${ }^{20}$ A more effective agent that can decrease sitosterol more than $40 \%$ is needed. Abnormal levels in diabetics should be reduced to $<4 \mathrm{mg} / \mathrm{L}$.

In the randomized clinical trial, IMPROVE-IT, (ezetimibe added to statin therapy after acute coronary syndromes), the benefit of the simvastatin-ezetimibe combination was "particularly pronounced in patients with diabetes mellitus", 21 probably because of reduction of sitosterol blood levels by ezetimibe. Ezetimibe and more effective agents may find a role for the management of diabetes. Diabetic patients with elevated sitosterol levels, or early signs of nephropathy or CVD, may be more effectively treated with ezetimibe plus statins and some dietary restrictions that include plant foods with high sitosterol content.

Foods that have a high content of sitosterol should be minimized, which include avocado, pistachio, peanuts, other nuts, chocolate, shell fish, canola, corn and coconut oil, bran rice, red rice, polished rice.

Third, the study did not aim to show that elevated sitosterol is a marker for CAD. Sitosterol is a cause of atheroma in patients with sitosterolemia and most likely a cause of atherosclerosis in patients with diabetes mellitus.

Fourth, a mild diabetic with elevated blood sitosterol may develop CAD; $34.37 \%$ of subjects with mild diabetes had abnormally high blood sitosterol. Only a rough estimation of severity of diabetes was required. Surprisingly, the study shows that sitosterol levels are elevated in mild diabetics; caution is required as prognosis is guarded for mild diabetics with elevated blood sitosterol. This important observation indicates that the pancreatic abnormality and degree of hyperglycemia bears no relation to the genetic intestinal disturbance that causes hyperabsorption of sitosterol. Thus, elevation can occur in mild diabetics and perhaps in nondiabetics. Studies are needed in nondiabetics, particularly in individuals aged 25 to 35 years with a family history of CAD and in patients admitted with acute coronary syndrome.

Lastly, among men with an absolute coronary risk $\geq 20 \%$ in 10 years as calculated using the PROCAM algorithm, high sitosterol concentrations were associated with an additional threefold increase in the incidence of coronary events. ${ }^{16}$ Because the intestinal genetic abnormality that exists in patients with diabetes mellitus is variable and may occur in those with mild diabetes regardless of glucose levels, it remains possible that some nondiabetics with CAD may have this genetic disturbance. The available data cannot confirm an increased risk in nondiabetics with sitosterol, but cannot rule it out either.

\section{CONCLUSION}

This study shows that 12 to 14 hours fasting blood sitosterol levels are elevated in patients with type II diabetes, particularly those with CAD. The study objective was achieved. Diabetic sitosterolemia and elevated LDL-C are the culprits causing rampant atheromatous CVD in diabetics. 
The genetic disease sitosterolemia is marked by mutations in either ABCG5 or G8 proteins ${ }^{8}$ that cause intestinal hyperabsorption of sitosterol. ${ }^{9,10}$ Normal 12-hour fasting sitosterol levels range from 0 to $5 \mathrm{mg} / \mathrm{L}$. The study shows that diabetics may achieve elevated sitosterol levels of 5.5 to $9.5 \mathrm{mg} / \mathrm{L}$. This is indeed diabetic sitosterolemia caused by a genetic abnormality at ABCG5 and ABCG8.

The study findings can be confirmed within weeks. This should engender outcome studies. Suppression of sitosterol absorption with ezetimibe and newly developed, more effective sitosterol absorption inhibitors should produce salutary outcomes for diabetics.

Ezetimibe is indicated as an adjunctive therapy to diet for the reduction of elevated sitosterol levels in patients with homozygous familial sitosterolemia. This study shows that diabetics have abnormally elevated blood sitosterol levels. Thus, ezetimibe is indicated as adjunctive therapy to diet for the reduction of elevated sitosterol in diabetics.

\section{REFERENCES}

1. Go AS, Mozaffarian D, Roger VL, Benjamin EJ, Berry JD, Borden WB, Bravata DM, Dai S, Ford ES, Fox CS, et al.; American Heart Association Statistics Committee and Stroke Statistics Subcommittee. Executive summary: heart disease and stroke statistics-2013 update: a report from the American Heart Association. Circulation 2013 Jan;127(1):143-152.

2. Centers for Disease Control and Prevention. National diabetes fact sheet: National estimates and general information on diabetes and prediabetes in the United States, 2011. Atlanta: US Department of Health and Human Services, Centers for Disease Control and Prevention; 2011.

3. Duckworth W, Abraira C, Moritz T, Reda D, Emanuele N, Reaven PD, Zieve FJ, Marks J, Davis SN, Hayward R, et al.; VADT Investigators. Glucose control and vascular complications in veterans with type 2 diabetes. N Engl J Med 2009 Jan;360(2):129-139.

4. ADVANCE Collaborative Group; Patel A, MacMahon S, Chalmers J, Neal B, Billot L, Woodward M, Marre M, Cooper M, Glasziou P, Grobbee D, et al. Intensive blood glucose control and vascular outcomes in patients with type 2 diabetes. N Engl J Med 2008 Jun;358(24):2560-2572.

5. Action to Control Cardiovascular Risk in Diabetes Study Group, Gerstein HC, Miller ME, Byington RP, Goff DC Jr, Bigger JT, Buse JB, Cushman WC, Genuth S, Ismail-Beigi F, Grimm RH Jr, et al. Effects of intensive glucose lowering in type 2 diabetes. N Engl J Med 2008 Jun;358(24):2545-2559.

6. Salen G, Horak I, Rothkopf M, Cohen JL, Speck J, Tint GS, Shore V, Dayal B, Chen T, Shefer S. Lethal atherosclerosis associated with abnormal plasma and tissue sterol composition in sitosterolemia with xanthomatosis. J Lipid Res 1985 Sep;26(9):1126-1133.

7. Bhattacharyya AK, Connor WE. Beta-sitosterolemia and xanthomatosis. A newly described lipid storage disease in two sisters. J Clin Invest 1974 Apr;53(4):1033-1043.

8. Lee MH, Lu K, Patel SB. Genetic basis of sitosterolemia. Curr Opin Lipidol 2001 Apr;12(2):141-149.

9. Hazard SE, Patel SB. Sterolins ABCG5 and ABCG8: regulators of whole body dietary sterols. Pflugers Arch 2007 Feb:453(5): 745-752.
10. Lally SE, Owens D, Tomkin GH. Sitosterol and cholesterol in chylomicrons of type 2 diabetic and non-diabetic subjects: the relationship with ATP binding cassette proteins G5 and G8 and Niemann-Pick C1-like 1 mRNA. Diabetologia 2007 Jan;50(1):217-219.

11. Nicolas A, Fatima S, Lamri A, Bellili-Muñoz N, Halimi JM, Saulnier PJ, Hadjadj S, Velho G, Marre M, Roussel R, et al. ABCG8 polymorphisms and renal disease in type 2 diabetic patients. Metabolism 2015 Jun;64(6):713-719.

12. Hadjadj S, Fumeron F, Roussel R, Saulnier PJ, Gallois $Y$, Ankotche A, Travert F, Abi Khalil C, Miot A, Alhenc-Gelas F, et al. Prognostic value of the insertion/deletion polymorphism of the ACE gene in type 2 diabetic subjects: results from the Non-insulin-dependent Diabetes, Hypertension, Microalbuminuria or Proteinuria, Cardiovascular Events, and Ramipril (DIABHYCAR), Diabete de type 2, Nephropathie et Genetique (DIAB2NEPHROGENE), and Survie, Diabete de type 2 et Genetique (SURDIAGENE) studies. Diabetes Care 2008 Sep;31(9):1847-1852.

13. Jaceldo-Siegl K, Lütjohann D, Sirirat R, Haddad E. Plant sterol concentration in plasma and intake in plant-based diets. FASEB J 2016 Apr;30(1 Suppl): 145-148.

14. Glueck CJ, Speirs J, Tracy T, Streicher P, Illig E, Vandegrift J. Relationships of serum plant sterols (phytosterols) and cholesterol in 595 hypercholesterolemic subjects, and familial aggregation of phytosterols, cholesterol, and premature coronary heart disease in hyperphytosterolemic probands and their first-degree relatives. Metabolism 1991 Aug;40(8):842-848.

15. Vergès B, Fumeron F. Potential risks associated with increased plasma plant-sterol levels. Diabetes Metab 2015 Feb;41(1):76-81.

16. Assmann G, Cullen P, Erbey J, Ramey DR, Kannenberg F, Schulte H. Plasma sitosterol elevations are associated with an increased incidence of coronary events in men: results of a nested case-control analysis of the Prospective Cardiovascular Münster (PROCAM) study. Nutr Metab Cardiovasc Dis 2006 Jan:16(1):13-21.

17. Miettinen TA, Railo M, Lepäntalo M, Gylling H. Plant sterols in serum and in atherosclerotic plaques of patients undergoing carotid endarterectomy. J Am Coll Cardiol 2005 Jun;45(11):1794-1801.

18. Miettinen TA, Gylling H, Strandberg T, Sarna S. Baseline serum cholestanol as predictor of recurrent coronary events in subgroup of Scandinavian Simvastatin Survival Study. Finnish 4S Investigators. BMJ 1998 Apr;316(7138):1127-1130.

19. Luister A, Schött HF, Husche C, Schäfers HJ, Böhm M, Plat J, Gräber S, Lütjohann D, Laufs U, Weingärtner O. Increased plant sterol deposition in vascular tissue characterizes patients with severe aortic stenosis and concomitant coronary artery disease. Steroids 2015 Jul;99(Pt B):272-280.

20. Salen G, von Bergmann K, Lütjohann D, Kwiterovich $P$, Kane J, Patel SB, Musliner T, Stein P, Musser B; Multicenter Sitosterolemia Study Group. Ezetimibe effectively reduces plasma plant sterols in patients with sitosterolemia. Circulation 2004 Mar:109(8):966-971.

21. Cannon CP, Blazing MA, Giugliano RP, McCagg A, White JA, Theroux P, Darius H, Lewis BS, Ophuis TO, Jukema JW, et al.; IMPROVE-IT Investigators. Ezetimibe added to statin therapy after acute coronary syndromes. N Engl J Med 2015 Jun;372(25):2387-2397. 